Loading

The Journal of the Canadian Game Studies Association

\title{
Harms Of Loot Boxes And Approaching Regulation In Singapore
}

\section{Hee Jhee Jiow and Jun Ming Lim}

Volume 14, Number 24, Fall 2021

URI: https://id.erudit.org/iderudit/1084840ar

DOI: https://doi.org/10.7202/1084840ar

See table of contents

Publisher(s)

Canadian Game Studies Association

ISSN

1923-2691 (digital)

Explore this journal

Cite this article

Jiow, H. \& Lim, J. (2021). Harms Of Loot Boxes And Approaching Regulation In Singapore. Loading, 14(24), 90-103. https://doi.org/10.7202/1084840ar

\section{Article abstract}

'Loot boxes' are a type of videogame monetization model that contains randomized rewards of varying rarities which emerged in recent years. The element of chance seeks to entice players into buying loot boxes in hopes of receiving a rare and desirable reward. The design of loot boxes has been identified to be addictive and to entice players to spend more money than they estimate they would. With links to addiction and gambling behaviours, loot boxes may cause social harm if unregulated. Singapore is not new to the videogaming scene and may seek to regulate loot boxes should it emerge as a social problem amongst Singaporeans. By acknowledging existing approaches towards regulating loot boxes and situating loot boxes in Singapore's social context, this paper explores Lessig's four modalities of constraint as a framework to hypothesize regulatory options for Singapore.
Copyright (c) Hee Jhee Jiow, Jun Ming Lim, 2021

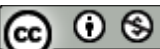

This document is protected by copyright law. Use of the services of Érudit (including reproduction) is subject to its terms and conditions, which can be viewed online.

https://apropos.erudit.org/en/users/policy-on-use/ 


\title{
Harms Of Loot Boxes and Approaching Regulation In Singapore
}

\author{
Jun Ming, Lim \\ Singapore Institute of Technology \\ ckronono@gmail.com \\ Hee Jhee, Jiow \\ Singapore Institute of Technology \\ jhee.jiow@singaporetech.edu.sg
}

\begin{abstract}
'Loot boxes' are a type of videogame monetization model that emerged in recent years, containing randomized rewards of varying rarities. The element of chance seeks to entice players into buying loot boxes in hopes of receiving a rare and desirable reward. The design of loot boxes has been identified to be addictive and to entice players to spend more money than they estimated they would. With links to addiction and gambling behaviours, loot boxes may cause social harm if not sufficiently regulated. Singapore is not new to the videogaming scene and may seek to regulate loot boxes should it emerge as a social problem amongst Singaporeans. By acknowledging existing approaches towards regulating loot boxes and situating loot boxes in Singapore's social context, this paper explores Lessig's four modalities of constraint as a framework to hypothesize loot box regulatory options for Singapore.
\end{abstract}

\section{Author Keywords}

Loot boxes, gambling, addiction, videogame monetization

\section{Introduction}

In seeking increased revenue from their products, videogame developers have adopted in-game loot into their monetization models, through the sale of videogame loot boxes for real-world money. Loot boxes in videogames are digital containers that hold a random item of varying rarity (Castillo, 2019), but odds of receiving a coveted item are usually low. Players purchase loot boxes for a chance at in-game items that increase the power level of their in-game avatars, or in-game cosmetic items that alter the look of their avatars, setting them aesthetically apart from the rest of the in-game community (Freedman, 2019). This shift in revenue model for game developers, however, has divided gaming communities. While the model has boosted revenue for developers, many gamers lament the potential ramifications, such as the need for additional expenditure beyond traditional shelf prices. This has drawn considerable ire from gaming communities as they predict a future where winners in games are decided more by gamers' financial status than their skill or effort. Potential links to gambling have also drawn concern over the unregulated state of loot boxes. 


\section{Literature Review}

Videogames have come a long way since the coin-eating machines found in arcades. In 2018, the videogames industry grossed $\$ 131$ billion in revenue (Lanier, 2019). Despite its growth, the industry faces stagnating price tags for games and ever-expanding budgets (Kain, 2018), shaving profits off revenue. This has led to videogame companies seeking to attract additional customer spending through innovative digital content. Digital content in videogames is often monetized through microtransactions, where consumers pay for extra content in-game such as loot boxes (Agarwal, 2017). Loot boxes can draw significant revenue as they are designed to be purchased repeatedly. To understand why this monetization model has become so increasingly popular, a brief look into the history of loot boxes in the videogame industry is necessary.

Loot boxes stem from "gachapon", a Japanese term for toy machines dispensing random prizes (Toto, 2012a). Introducing "gachapon" into videogames generated significant revenue, with the Japanese puzzle game "Puzzle and Dragons" becoming the first mobile game to gross USD 1 billion in 2013, underlining the success of the loot box monetization model (Jordan, 2013). Blizzard Entertainment subsequently brought loot boxes into popular consciousness with their shooter game Overwatch, attributing up to USD2 billion of revenue to loot boxes (Thubron, 2018).

\section{Consumer Response to Loot Boxes}

Despite providing significant revenue to publishers, loot boxes are not necessarily an experience that gamers enjoy. Initially, games such as Team Fortress 2 and Overwatch introduced cosmetic loot boxes, containing digital content that alters the aesthetics in a player's gaming experience, also known as 'skins' (Freedman, 2019). Cosmetic content allowed players to uniquely customize the aesthetics of players' avatars, while maintaining a fair play environment. However, publishers eventually experimented with loot boxes that alter the fairness of this environment. Star Wars Battlefront II, a game from Electronic Arts (EA), aggressively marketed loot boxes before its launch (Webster, 2018). Dissatisfied gamers declared a boycott on Star Wars Battlefront II for being a full-priced game that contained performance-boosting microtransactions, providing an unfair advantage in terms of access to coveted characters. The boycott made the game one of the industry's largest flops, with EA's official response being criticized on Reddit for their explanation of implementing loot boxes to "provide a sense of pride and achievement for unlocking different heroes" (MBMMaverick, 2017).

Post-fiasco, EA turned off the microtransactions in the game. In the aftermath, EA's chief design officer Patrick Söderlund acknowledged in an interview that their decisions were wrong and that there was a lot to learn from the community (Webster, 2018), which signaled a shift in EA's acceptance to self-regulate and set boundaries when monetizing their videogames.

\section{Industry Response to Loot Boxes}

A key factor for the popularity of loot boxes is the identification of consumers with significant spending power. These consumers are known as "whales" - gamers who spend large amounts of money in games to distinguish themselves from others (Dreier et al., 2017). Such whales have been known to spend upwards of a thousand dollars across multiple microtransactions (Agarwal, 2017; Rose, 2013). Despite their expenditures, some whales regret their purchases, with many falling into debt (Gambling Health Alliance, 2020; Rose, 2013). Game developers seek to attract 
whales into spending money on their games, and methods include patented behaviour tracking and bespoke in-game microtransaction offerings based on their in-game spending habits (King et al., 2019). For example, in 2017 publisher Activision-Blizzard patented a method of matchmaking players with others using skins bought from loot boxes, associating skilled gameplay with the urge to buy loot boxes (Alexandra, 2017). The design behind the opening of loot boxes makes for an exciting spectacle for consumers, with animations and colour-coding of rare rewards building anticipation and excitement (Wiltshire, 2017). Such sales designs push players towards spending on microtransactions, and will only escalate in magnitude as monetization models seek to capture and stimulate spending behaviours amongst game players.

Despite industry fervour in hawking loot boxes, the industry has shown self-awareness towards loot boxes as a problem. This was largely sparked by the investigations into loot boxes conducted by the Federal Trade Commission (FTC) of the United States (Federal Trade Commission, 2020). During the workshop, the Entertainment Software Agency (ESA) announced that its members had entered into a commitment to provide transparency on loot box probabilities no later than 2020 (ESA, 2019), signifying industry intent to placate the FTC and potentially soften their investigations. However, other industry partners argued that transparency through disclosing of loot box odds is insufficient (Vance et al., 2019). In the workshop, Consumer Reports outlined how behavioural design in games aims to subtly nudge players into spending money on microtransactions such as loot boxes, and can be manipulative towards consumers (Vance et al., 2019). However, the panel did acknowledge the difficulty in achieving a standardized regulatory framework. These statements highlight how current self-regulatory measures alone are inadequate.

Loot boxes in videogames have so far been identified as immensely problematic. They have been linked to problem gambling, (Castillo, 2019; Cerezo, 2019; Zendle \& Cairns, 2018), with children and youths being most vulnerable to overspending (Calado et al., 2014), and their design as a product can foster compulsive and addictive behaviours amongst gamers (Wiltshire, 2017). Consumers of videogames in Singapore may struggle with addictive behaviours found in such immersive technologies, such as problem gambling and excessive spending. With South-east Asia predicted to generate \$4.6 billion in videogame revenue in 2019 (Newzoo, 2019) and Singapore warming up towards competitive videogaming (Channel NewsAsia, 2019), understanding loot boxes and addictive behaviours amongst gamers would help illuminate social behaviours and economic activity in cyberspace. As such, developing regulatory frameworks for Singapore can benefit policymaking, as Singapore moves towards nationwide digital transformations (Government of Singapore, 2019).

In a speech addressed to the 5th Symposium on Gambling Regulation and Crime, the Minister for Manpower and Second Minister for Home Affairs Josephine Teo highlighted loot boxes as "products across various modes of gambling or gaming" (Teo, 2019), calling for new regulations that can address these randomized products of chance. However, developing regulatory frameworks for videogames can be complex, as excessive laws may stifle the industry's economy. For this paper, Lawrence Lessig's four modalities of constraint on regulating cyberspace activity (Lessig, 2006) will be used as a theoretical framework in approaching regulation of loot boxes in Singapore. 


\section{Adopting Lessig's Four Modalities of Constraint}

As digital experiences shared amongst users in cyberspace increase, Lessig noted that experiences and behaviours in cyberspace could be influenced through various methods of regulation, with code being an essential method (Lessig, 2006). Code dictates what behaviours are permitted, constraining what users can do in cyberspace. Code exemplifies values and provides control. In conceptualizing regulation, Lessig introduced four modalities that constrain cyberspace behaviours, namely laws (legal constraints), norms (social interactions), markets (prices and choice) and architecture (design in technology) (Lessig, 2006). Laws serve to regulate and curb undesired behaviour, and often utilize architecture as a means to achieve this, as for example when outlawing speeding (law) and installing speed bumps (architecture) (Lessig, 2006). Speeding may also be socially unacceptable, thus making such behaviours undesirable as norms. Receiving speeding tickets may cause car insurance premiums to increase, so the markets exert further influence on curbing unwanted behaviour. Using Lessig's four modalities of constraint has proved fruitful to explore cyberspace behaviours in Singapore (Jiow, 2013), and can provide an opportunity to hypothesize sustainable regulatory measures. These constraints are interlinked and may be interdependent, and it is expected that elements of other modalities will emerge while discussing each modality of constraint.

\section{Law}

A major step towards facilitating legal constraints on the distribution of loot boxes in videogames would be to provide a clearer definition of what a player's money is worth in games of chance, given that consumers prescribe monetary value to loot box rewards that they are willing to spend money on. Furthermore, the act of selling digital goods in videogames, known as real-money trading (RMT), is an issue prevalent in many online videogames. Game service providers may expressively forbid RMT activities, but it has been observed to be inefficient in restricting such activities (Digital, Culture, Media and Sport Committee, 2019). Loot box contents may be traded through the selling of game service accounts or in-game trading after money is received (Toto, 2012b). This creates complications in defining money's worth in loot boxes and to some extent, allows loot boxes to be played for cash prizes. Ultimately, regulation should seek to tread a middle ground for both the state and the free market-constraining the harms of excessive loot box consumption, whilst retaining the opportunity to meet supply with demand.

To identify and formulate regulations on loot boxes using laws, considerations must be made of Singapore's stance on gambling and economic trade. Singapore's Remote Gambling Act is one law enacted in 2015 (Remote Gambling Act 2014, 2015) aimed at combating online gambling activities, which places the Act in a position to effectively target and regulate loot boxes. The Remote Gambling Act of Singapore defines gambling as "staking money's worth on an outcome", "playing a game of chance for money's worth", and "any game, method, device, scheme or competition whereby money or money's worth is distributed or allotted in any manner depending upon or to be determined by chance or lot", and was enacted to primarily prevent crime and protect young and vulnerable persons from the harms of gambling (Digital, Culture, Media and Sport Committee, 2019; Remote Gambling Act 2014, 2015). However, the Infocomm Media Development Authority of Singapore clarified that they would not target videogames that had elements of gambling that do not involve monetary or real-world prizes (IMDA, 2015). This means that should Singapore decide to outlaw elements of gambling experiences in videogames, new 
laws will be necessary, and it would create tensions amongst videogame companies who employ loot boxes as part of their monetization strategies in their videogames. Subsequently, it risks Singapore's high rankings on economic freedom (The Heritage Foundation, 2019), as curbing loot boxes may turn videogame companies away from doing business in Singapore, a global trade hub.

With Singapore's free-market standards, laws that outright ban loot boxes, akin to Belgium's ban (Taylor, 2018), would be highly unlikely, though not impossible. Although definitions on gambling are clear, definitions on games of chance are blurry. In 2018, Singapore saw vending machines that dispensed mystery prizes for a small fee (Tay, 2018), resembling a real-world equivalent of loot boxes. These vending machines were eventually outlawed by the state (Singapore Police Force, 2018), and defined as gambling. This ban demonstrated the state's stance on gambling activities, but was criticized as an arbitrary move, as many similar activities involve games of chance (Tay, 2018). Businesses tend to be classified as gambling when the monetary value of the prizes they offer can be more easily determined.

Despite the difficulty in ascribing a monetary value to digital items in videogame loot boxes, the allure of a rare prize is essentially the marketing pitch of both mystery prize vending machines and digital loot boxes. Despite the impact on economy and business for videogame companies, acknowledgement of loot boxes as a novel product incorporating gambling makes a ban on loot boxes a possible last resort for the state (Singapore Police Force, 2018), should it evolve into a huge social issue for Singaporeans. If avoiding such drastic measures is preferred in order to maintain the viability of the videogame industry in Singapore, the State must encourage alternative monetization models for videogames, which is discussed in the Markets modality section of this paper.

\section{Social Norms}

The fracas around the predatory nature of loot boxes in video games has so far received momentum and interest from various regulatory authorities around the world (Akimoto, 2012; Digital, Culture, Media and Sport Committee, 2019; Federal Trade Commission, 2019; Taylor, 2018). However, social norms that surround videogaming and loot boxes remain shrouded. The Star Wars Battlefront II loot box debacle gives some insight into how players were vehemently against loot boxes as a monetization model, with the backlash causing EA, the publisher of Star Wars Battlefront II, to suffer an 8.5\% drop in share prices, a loss valued at USD\$3.1 billion (Kain, 2017). With this incident, the aversion and controversy surrounding loot boxes created a negative image that severely constrained the profitability of loot boxes. The impact of the boycott gained enough traction to warrant self-regulation amongst game publishers, with games such as Fortnite, Call of Duty: Modern Warfare and Rocket League stepping away from loot boxes altogether, and instead offering "battle pass" type microtransactions (Jordan, 2018). "Battle passes" are a type of milestone microtransaction where gamers purchase access to a list of rewards that are provided as gamers invest playtime into games (Davenport, 2018; Jordan, 2018).

The case study of the Star Wars Battlefront II incident (MBMMaverick, 2017) highlights a set of social norms amongst gamers who identify the profit-making objectives of videogame publishers as problematic, luring gamers into spending unnecessary money on features of a game (Busby, 2019; King et al., 2019), and how their community actions effectively prohibit the profitability of the loot box monetization model. One reason behind the development of these norms that help 
build an aversion towards loot boxes would be the concept of "pay to win", or "P2W" (Rester, 2019 , p. 223), where emerging loot box products contain digital content such as weapons or characters that are stronger than non-loot box counterparts, allowing gamers to gain an advantage during gameplay. A study by Qutee, a data analytics platform, found that $98 \%$ of respondents felt that "pay to win" was unacceptable, as respondents felt that it contributes to unfair play conditions where players are only as strong as their disposable income (Qutee, 2018). Continued debate amongst gamers on what constitutes value for their dollar can steer and potentially accelerate industry self-regulation, further constraining videogame companies' behaviours and their preference for the loot box monetization model.

Loot boxes remain a product of debate amongst lawmakers as a novel digital product. As earlier discussed, social norms held amongst gamers can generate enough momentum amongst their communities to effect change in the markets (Rester, 2019; Webster, 2018). Although social norms over loot boxes are largely negotiated between consumer and game publishers, their influence can cross over towards regulating and constraining sales through supply and demand, which will be explored next in the Markets modality of constraint.

\section{Markets}

It is in the financial interest of videogame companies to ensure that their monetization models remain accepted by their player base, to ensure continued revenue. In 2019, free-to-play games drew a revenue of USD \$87.1 billion for the videogames industry, an increase of 6\% from 2018 (SuperData, 2020). As previously discussed on the social aversion to loot box monetization, videogame, publishers have opted to self-regulate and adopt alternative models, such as battle passes (Davenport, 2018). Thus, it can be argued that alternative monetization models that appeal to a customer base averse to loot boxes can be effective in transitioning away from those loot box monetization models.

Although battle pass monetization models have become popular (Davenport, 2018; Jordan, 2018), there are limits to how much they can regulate loot boxes. "Gacha" games that heavily involve the use of loot box mechanics for progression in their games cannot feasibly migrate towards a battle pass model, as "Gacha" design is centred around collecting a variety of avatars and equipment, with rarer versions being more coveted as they may be statistically stronger than their less-rare counterparts (Klepek, 2017; Toto, 2012a). Compared to game genres such as Multiplayer Online Battle Arenas (MOBA) (Mora-Cantallops \& Sicilia, 2018) and shooter style games, Gacha game design revolves around obtaining high-rarity and stronger avatars to complete missions (Klepek, 2017), rather than on an emphasis on fairness and skilled play. Battle pass monetization models tend to reward cosmetic content such as alternative in-game skins for avatars or equipment (Davenport, 2018), maintaining the emphasis on fairness. This would directly contradict Gacha design and therefore not be feasible to implement. As a result, publishers may steer away from Gacha genres as part of their self-regulation considerations.

As loot boxes are digital content, traditional concepts of supply and demand (Lessig, 2006, p. 122) are not applicable. Supply of loot boxes is infinite in cyberspace, and the rarity of randomized rewards is designed to draw consumers in to repeatedly purchase loot boxes until they obtain something they want (Alexandra, 2017; Castillo, 2019; Zagal et al., 2013). As such, videogame publishers will seek to drive demand for loot boxes to increase sales. For loot boxes that offer 
cosmetic rewards, these rewards will typically feature aesthetical content that allows players to customize their gameplay experience and distinguish themselves. As a result, a reliance on other modalities of constraint will be necessary to achieve regulation in markets.

In this section, it is observed that social norms amongst consumers can force market selfregulation, with videogame companies adopting alternative monetization such as battle passes. However, data is inconclusive on whether battle passes are more profitable than loot boxes for videogaming companies, and battle passes are not even feasible for all videogame genres that market loot boxes. With loot boxes enjoying an infinite supply like all digital products, the Markets modality in Lessig's modalities of constraint is not an effective regulator of constraining the sale of loot boxes, nor of constraining the behaviours of videogaming companies in marketing loot boxes. This would be one limitation on applying Lessig's framework to regulating loot boxes.

\section{Architecture}

Lessig (2006) defines architectural constraints as those that seek to curb behaviours by design. In the context of loot boxes, it would refer to making the purchase of loot boxes difficult or may involve regulating the design of loot boxes to be less predatory or less misleading. Architectural solutions conceptualized include removing the 'Audio-Visual Design of Loot Box Opening' (King \& Delfabbro, 2019, p. 172), which involves a celebratory experience when opening loot boxes that reinforces addictive behaviours in consumers (Larche et al., 2019). Another would be 'Removal of Repeat or Duplicate (i.e. Contextually Worthless) Rewards' (King \& Delfabbro, 2019, p. 172), which prevents players from receiving duplicates from obtainable rewards in a loot box. Essentially, these are ethical countermeasures that seek to reduce the potential harms of loot boxes. However, not all proposed solutions are feasible. Most of the proposed solutions are unlikely to be implemented by the videogame industry without some sort of regulatory encouragement from government states (Xiao \& Henderson, 2019), as it impacts profitability.

From the above discussion, to provide clarity on setting industry regulations on loot boxes in Singapore it would be fruitful to break away from arguments of whether loot boxes constitute gambling, and focus on the concept of 'predatory monetization' (King et al., 2019). For example, the removal of audio-visual design in opening loot boxes would be consistent with how Singapore removes advertising in addictive substances such as tobacco, instead placing graphic imagery to combat said addiction (Abu Baker \& Chia, 2019). Architectural solutions are numerous, as seen in recommendations by King and Delfabbro, but have not as yet provided any miracle cures. As earlier discussed in the Law section, some of Singapore's regulations on gambling involves visit and spending limits on top of age limits (NCPG, 2019). The state can consider this in loot box expenditures by requesting videogame publishers to set purchase limits (King \& Delfabbro, 2019, p. 174) which can prevent excessive spending, remaining consistent in their regulation of addictive activities.

\section{Discussion}

Using Lessig's four modalities of constraint as a framework to theorize regulation, we identified several regulatory options and situated them in Singapore's economic and cultural environment to assess their feasibility and provide a holistic view on the issues that surround, and often shroud, loot boxes. 


\section{Consumption Tax And Removal Of Audio-Visual Experiences In Loot Boxes}

In the Law section, we introduced Singapore's climate on regulating traditional gambling, and a case study of similar real-world vending machines. Considering its business-friendly environment, it would be unlikely for Singapore to take up regulations that may hamper the videogame industry's growth like the ban on loot boxes by Belgium and the Netherlands (Taylor, 2018). To constrain the sale of loot boxes through law and markets, Singapore could explore a tiered tax on buying increasing amounts of loot boxes in a specific timeframe, to discourage overconsumption behaviours and encourage players to stagger their purchases. This is in line with Singapore's sin taxes (Shaffer, 2014), designed to tax products that are associated with social ills. One immediate limitation would be that this drives away smaller videogame companies who may not profit enough to sustain their business as a result of excessive taxation. Taxing loot boxes similarly impacts videogame design if the content of loot boxes is necessary for gameplay experiences. An increasing tax may cause undue negative gameplay experience for consumers as well, and may become a pseudo-ban on loot boxes. As a measured response, the state could explore mandating the removal of audio-visual content in videogames that utilize variable-ratio reinforcement schedules (Larche et al., 2019). The removal of such gameplay experiences that reinforce addictive behaviours could help restrain consumers from developing the urge to overspend on loot boxes. Furthermore, adopting loot box terminologies in official anti-gambling campaigns can thrust addictive digital products into popular consciousness, and help consumers make more informed decisions.

\section{Ethical Frameworks and Alternative Monetization}

A case study on consumer outrage also provided insight into how social norms can constrain the sale of loot boxes. Consumer aversion to loot boxes can push videogame publishers to selfregulate, shifting from a loot box monetization model towards alternatives such as battle passes (Ashley, 2018; Davenport, 2018). Customer dissatisfaction can form part of the social norms amongst consumers, creating a negative image of loot boxes that limits their sales. In the Markets section, more on industry self-regulation was identified, and analysis on the feasibility of battle passes showed that they could be less problematic than addictive loot boxes (Davenport, 2018).

In the Social Norms section, consumer trends can constrain the sale of loot boxes. These trends have been largely focused on the ethics of monetizing video games (Neely, 2019), and the theme of ethics should be considered when using other modalities of constraint to regulate the sale of loot boxes through markets. For example, state intervention through law may provide an ethics framework for loot boxes to promote social responsibility in the videogame industry. An ethics framework would incorporate aspects of ethical game design, transparency and accountability (King \& Delfabbro, 2019). Supply of loot boxes may be constrained by law by preventing the use of virtual currency to obfuscate awareness of player spending (King \& Delfabbro, 2019, p. 170).

Collective perceptions of value from loot boxes can shift market sentiment, creating an interdependency between the two modalities of constraint for loot boxes. Although not immediately useful for state regulation, collective sentiment is particularly useful for the design of an ethical framework for monetizing games. This framework can help Singapore incentivize socially responsible business practices in the videogames industry. Regulators approaching an ethical framework should focus on collecting data on videogaming consumer habits and opinions, 
in order to mitigate how videogame publishers capitalize on player behaviours to encourage spending.

\section{Tax Breaks And Age Limits}

Lastly, in the Architecture section, existing studies outlined how concepts of ethical game design and social responsibility may guide regulation options, acknowledging the limited feasibility for some recommended regulations due to the economic interests of videogame publishers. In consideration of these factors, rather than attempting to harshly regulate or impede the sale of loot boxes, an alternative to banning loot boxes includes encouraging ethical monetization of videogames through state incentives such as tax breaks (Xiao \& Henderson, 2019) within an ethical framework promoting social responsibility. Tax breaks could be given to game publishers who integrate constraints on buying loot boxes or remove them entirely. However, the feasibility of implementing tax breaks would be questionable, as there are game genres whose reliance on luck and elements of games of chance may not qualify for such incentives, essentially penalizing the freedom of design and game variety.

A less disruptive constraint would be age limits that can be implemented on consumers to protect youths. With MyInfo, a service offered by SingPass (GovTech Singapore, 2020), age verification measures can be implemented on consumers when they sign up for an account with videogame providers that hawk loot boxes. Compliance with state architecture such as MyInfo may facilitate a soft regulatory approach from the state.

\section{Conclusion}

The introduction of loot boxes by the videogame industry produced significant revenue and has become a cultural phenomenon in videogames. However, loot boxes have also shown their potential to damage a growing videogaming demographic, through the promotion of addictive gambling behaviours. Using Lessig's four modalities of constraint, Singapore could spearhead regulatory initiatives that may be low impact on the videogaming industry, such as reducing audiovisual material found to reinforce purchasing behaviours, and introducing consumption taxes and age limits on access to real-world currency products in-game. These provisional measures would seek to constrain behaviours related to addiction and gambling through the purchase of loot boxes. This paper has also identified how social norms in videogaming communities can inform future research on collectively perceived unethical practices in the videogame industry, which future qualitative research can focus on when studying the harms caused by loot boxes. The negative impacts of loot boxes have consequences on Singapore's growing videogaming population, and with continued study into the local norms around thm, regulators can develop effective measures on loot boxes to encourage ethical business practices. 


\section{References}

Abu Baker, J., \& Chia, L. (2019, February 11). Bill to enforce plain packaging for tobacco products passed in Parliament. CNA.

https://www.channelnewsasia.com/news/singapore/plain-packaging-for-tobaccocigarettes-bill-passed-parliament-11230234

Agarwal, P. (2017, November 19). Economics of Microtransactions in Video Games. Intelligent Economist. https://www.intelligenteconomist.com/economics-ofmicrotransactions/

Akimoto, A. (2012, May 16). Japan's social-gaming industry hindered by government's antigambling move. The Japan Times Online. https://www.japantimes.co.jp/life/2012/05/16/digital/japans-social-gaming-industryhindered-by-governments-anti-gambling-move

Alexandra, H. (2017, October 17). Activision Patents Matchmaking That Encourages Players To Buy Microtransactions. Kotaku. https://kotaku.com/activision-patents-matchmakingthat-encourages-players-1819630937

Ashley, C. (2018, May 21). What Fortnite's Battle Pass gets right. Polygon. https://www.polygon.com/fortnite/2018/5/21/17376178/fortnite-season-4-battle-passskins-loot-boxes

Busby, M. (2019, November 22). Loot boxes increasingly common in video games despite addiction concerns. The Guardian. https://www.theguardian.com/games/2019/nov/22/loot-boxes-increasingly-common-invideo-games-despite-addiction-concerns

Calado, F., Alexandre, J., \& Griffiths, M. (2014). Mom, Dad It's Only a Game! Perceived Gambling and Gaming Behaviors among Adolescents and Young Adults: An Exploratory Study. International Journal of Mental Health \& Addiction, 12(6), 772794. https://doi.org/10.1007/s11469-014-9509-y

Castillo, D. J. (2019). Unpacking the Loot Box: How Gaming's Latest Monetization System Flirts with Traditional Gambling Methods. Santa Clara Law Review, Issue 1, 165.

Cerezo, A. H. (2019). Loot Boxes: Minors Facing Dissembled Online Gambling. Revista Juridica de Castilla y Leon, 25.

Channel NewsAsia. (2019, October 9). 20 athletes break new ground to represent Singapore in e-sports at SEA Games 2019. CNA. https://www.channelnewsasia.com/news/sport/esports-singapore-represent-sea-games2019-11983636 
Davenport, J. (2018, July 5). Battle passes are replacing loot boxes, but they're not necessarily a better deal. PC Gamer. https://www.pcgamer.com/battle-passes-are-replacing-lootboxes-but-theyre-not-necessarily-a-better-deal/

Digital, Culture, Media and Sport Committee. (2019). Immersive and addictive technologies (15 of Session 2017-19). House of Commons. https://publications.parliament.uk/pa/cm201719/cmselect/cmcumeds/1846/184602.htm

Dreier, M., Wölfling, K., Duven, E., Giralt, S., Beutel, M. E., \& Müller, K. W. (2017). Free-toplay: About addicted Whales, at risk Dolphins and healthy Minnows. Monetarization design and Internet Gaming Disorder. Addictive Behaviors, 64, 328-333. https://doi.org/10.1016/j.addbeh.2016.03.008

ESA. (2019, August 7). Video Game Industry Commitments to Further Inform Consumer Purchases. Entertainment Software Association. https://www.theesa.com/perspectives/video-game-industry-commitments-to-furtherinform-consumer-purchases/

Federal Trade Commission. (2020, August 14). FTC Staff Issue Perspective Paper on Video Game Loot Boxes Workshop. Federal Trade Commission. https://www.ftc.gov/newsevents/press-releases/2020/08/ftc-staff-issue-perspective-paper-video-game-loot-boxesworkshop

Freedman, A. E. (2019, August 9). What Are Loot Boxes? Gaming's Big New Problem, Explained. Tom's Guide. https://www.tomsguide.com/us/what-are-loot-boxesmicrotransactions, news-26161.html

Gambling Health Alliance (2020, December 23) Over 1 in 10 young gamers get into debt by buying loot boxes. Gambling Health Alliance. https://www.rsph.org.uk/aboutus/news/over-1-in-10-young-gamers-get-into-debt-because-of-loot-boxes.html

Government of Singapore. (2019, November 12). Transforming Singapore. Smart Nation Singapore. http://www.smartnation.sg/why-Smart-Nation/transforming-singapore

GovTech Singapore. (2020, April 16). MyInfo. https://www.tech.gov.sg/products-andservices/my-info/

IMDA. (2015). Remote Gambling Act: Clarifications on the Scope of Social Games. Infocomm Media Development Authority. http://www.imda.gov.sg/news-and-events/MediaRoom/archived/mda/Media-Releases/2015/remote-gambling-act-clarifications-on-thescope-of-social-games

Jiow, H. J. (2013). Cyber Crime in Singapore: An Analysis of Regulation based on Lessig's four Modalities of Constraint. International Journal of Cyber Criminology, 7(1), 18-27.

Jordan, J. (2013, February 4). It's official: Puzzle \& Dragons is the first mobile game to \$1 billion in revenue. Pocketgamer.Biz. https://www.pocketgamer.biz/asia/news/57076/itsofficial-puzzle-and-dragons-is-the-first-mobile-game-to-1-billion-in-revenue/ 
Jordan, J. (2018, July 2). Why Fortnite's monetisation is easy to copy but its success hard to replicate. PocketGamer. https://www.pocketgamer.com/articles/077950/why-fortnitesmonetisation-is-easy-to-copy-but-its-success-hard-to-replicate/

Kain, E. (2017, November 28). EA Shares Plummet After "Star Wars: Battlefront II" Loot Box Fiasco. Forbes. https://www.forbes.com/sites/erikkain/2017/11/28/ea-shares-plummetafter-star-wars-battlefront-ii-loot-box-fiasco/

Kain, E. (2018, February 13). Should Video Games Be More Expensive? 3 Reasons Why That Doesn't Make Sense. Forbes. https://www.forbes.com/sites/erikkain/2018/02/13/hereare-3-reasons-why-video-games-should-actually-cost-less-than-60/

King, D. L., \& Delfabbro, P. H. (2019). Video Game Monetization (e.g., 'Loot Boxes'): A Blueprint for Practical Social Responsibility Measures. International Journal of Mental Health \& Addiction, 17(1), 166-179. https://doi.org/10.1007/s11469-018-0009-3

King, D. L., Delfabbro, P. H., Gainsbury, S. M., Dreier, M., Greer, N., \& Billieux, J. (2019). Unfair play? Video games as exploitative monetized services: An examination of game patents from a consumer protection perspective. Computers in Human Behavior, 101, 131-143. https://doi.org/10.1016/j.chb.2019.07.017

Klepek, P. (2017, January 19). Nintendo's Mobile “Fire Emblem" Is a “Gacha” Game, Here's What That Means. Vice. https://www.vice.com/en us/article/wnn834/nintendos-mobilefire-emblem-is-a-gacha-game-heres-what-that-means

Koeder, M. J., \& Tanaka, E. (2017). Game of chance elements in free-to-play mobile games. A freemium business model monetization tool in need of self-regulation?

Lanier, L. (2019, May 1). Video Games Could Be a \$300 Billion Industry by 2025 (Report). Variety. https://variety.com/2019/gaming/news/video-games-300-billion-industry-2025report-1203202672/

Larche, C. J., Chini, K., Lee, C., Dixon, M. J., \& Fernandes, M. (2019). Rare Loot Box Rewards Trigger Larger Arousal and Reward Responses, and Greater Urge to Open More Loot Boxes. Journal of Gambling Studies. https://doi.org/10.1007/s10899-01909913-5

Lessig, L. (2006). Code: Version 2.0 (Sydney Jones Library Law Collection 2; [2nd ed.]). Basic Books.

MBMMaverick. (2017, November 12). Seriously? I paid $80 \$$ to have Vader locked? Reddit. https://www.reddit.com/r/StarWarsBattlefront/comments/7cffob/seriously_i_paid_80 to have vader locked/

Mora-Cantallops, M., \& Sicilia, M.-Á. (2018). MOBA games: A literature review. Entertainment Computing, 26. https://doi.org/10.1016/j.entcom.2018.02.005

NCPG. (2019, July 2). NCPG - FAQ. https://www.ncpg.org.sg/en/Pages/exclusionsfaq.aspx 
Neely, E. L. (2019). Come for the Game, Stay for the Cash Grab: The Ethics of Loot Boxes, Microtransactions, and Freemium Games. GAMES AND CULTURE. https://doi.org/10.1177/1555412019887658

Newzoo. (2019, March 25). Navigating the World's Fastest-Growing Games Market: Insights into Southeast Asia. Newzoo. https://newzoo.com/insights/articles/navigating-theworlds-fastest-growing-games-market-insights-into-southeast-asia/

Qutee. (2018). Gaming Today-Gaming in 2018 (Gaming Today). Qutee. https://s3.amazonaws.com/qutee-reports/Qutee-Gaming-Today-Report.pdf

Remote Gambling Act 2014, Pub. L. No. 24 of 2014 (2015). https://sso.agc.gov.sg/Act/RGA2014 Rester, N. (2019). Insert Coin: Pay-to-Win and the Loot Box Dilemma. 23, 221-228. http://doi.org.liverpool.idm.oclc.org/10.1089/glr2.2019.2346

Rose, M. (2013, July 9). Chasing the Whale: Examining the ethics of free-to-play games. Gamasutra. https://www.gamasutra.com/view/feature/195806/chasing the whale examining the . php

Shaffer, L. (2014, February 21). Singapore to tax sin instead of the wealthy. CNBC. https://www.cnbc.com/2014/02/21/singapore-to-tax-sin-instead-of-the-wealthy.html

Singapore Police Force. (2018, August 16). Police Advisory On Vending Machines Dispensing Mystery Prizes In Singapore. Singapore Police Force. http:/www.police.gov.sg/MediaRoom/News/20180816_advisory_vending_machine dispensing_mystery prizes_cid

SuperData. (2020). 2019 Year In Review: Digital Games and Interactive Media (p. 23). https://www.superdataresearch.com/reports/2019-year-in-review

Tay, T. F. (2018, August 28). Mystery prize vending machine games can be fraudulent, say police. The New Paper. https://www.tnp.sg/news/singapore/mystery-prize-vendingmachine-games-can-be-fraudulent-say-police

Taylor, H. (2018, April 25). EA, Activision Blizzard, and Valve found in breach of Belgian gambling laws. GamesIndustry.Biz. https://www.gamesindustry.biz/articles/2018-04-25three-industry-leading-publishers-found-in-breach-of-belgian-gambling-laws

Teo, J. (2019, August 29). 5th Symposium on Gambling Regulation and Crime-Speech by Mrs Josephine Teo, Minister for Manpower and Second Minister for Home Affairs [Speech]. http://www.mha.gov.sg/newsroom/speeches/news/5th-symposium-on-gamblingregulation-and-crime-speech-by-mrs-josephine-teo-minister-for-manpower-and-secondminister-for-home-affairs

The Heritage Foundation. (2019). Singapore Economy: Population, GDP, Inflation, Business, Trade, FDI, Corruption (2019 Index of Economic Freedom). The Heritage Foundation. http://www.heritage.org/index/country/singapore 
Thubron, R. (2018, February 12). Over half of Activision Blizzard's $\$ 7.16$ billion yearly revenue came from microtransactions. TechSpot.

https://www.techspot.com/news/73230-over-half-activision-blizzard-716-billion-yearlyrevenue.html

Toto, S. (2012a, February 21). Gacha: Explaining Japan's Top Money-Making Social Game Mechanism [Social Games] - Kantan Games Inc. CEO Blog. https://www.serkantoto.com/2012/02/21/gacha-social-games/

Toto, S. (2012b, May 14). What Does "Real-Money Trading” Of Virtual Items Mean? [Social Games] - Kantan Games Inc. CEO Blog. KantanGames. https://www.serkantoto.com/2012/05/14/real-money-trading-gree-dena-mobage/

Vance, P., Laitin, A., Whyte, K., \& F. Johnson, A. (2019, August 7). Panel 3: A Level Playing Field - What's Fair Game? Inside the Game: Unlocking the Consumer Issues Surrounding Loot Boxes - An FTC Workshop, 400 7th St SW, Washington, DC 20024.

Webster, A. (2018, April 13). EA says it's learned from Star Wars Battlefront controversy, vows to 'be better.' The Verge. https://www.theverge.com/2018/4/13/17230874/ea-starwars-battlefront-2-loot-box-patrick-soderlund-interview

Wiltshire, A. (2017, September 28). Behind the addictive psychology and seductive art of loot boxes. PC Gamer. https://www.pcgamer.com/behind-the-addictive-psychology-andseductive-art-of-loot-boxes/

Xiao, L. Y., \& Henderson, L. L. (2019). Towards an Ethical Game Design Solution to Loot Boxes: A Commentary on King and Delfabbro. International Journal of Mental Health and Addiction, 1. https://doi.org/10.1007/s11469-019-00164-4

Zagal, J. P., Björk, S., \& Lewis, C. (2013). Dark Patterns in the Design of Games.

Zendle, D., \& Cairns, P. (2018). Video game loot boxes are linked to problem gambling: Results of a large-scale survey. PLOS ONE, 13(11), e0206767. https://doi.org/10.1371/journal.pone.0206767

Zendle, D., Meyer, R., \& Over, H. (2019). Adolescents and loot boxes: Links with problem gambling and motivations for purchase. ROYAL SOCIETY OPEN SCIENCE, 6(6). https://doi.org/10.1098/rsos.190049 